\title{
Measuring the Quality of Clinical Skills Mobile Apps for Student Learning: Systematic Search, Analysis, and Comparison of Two Measurement Scales
}

Tehmina Gladman ${ }^{1}$, PhD; Grace Tylee ${ }^{2}$, MBChB; Steve Gallagher ${ }^{3}$, PhD; Jonathan Mair ${ }^{2}$, MBChB; Rebecca Grainger ${ }^{1}$, $\mathrm{PhD}$

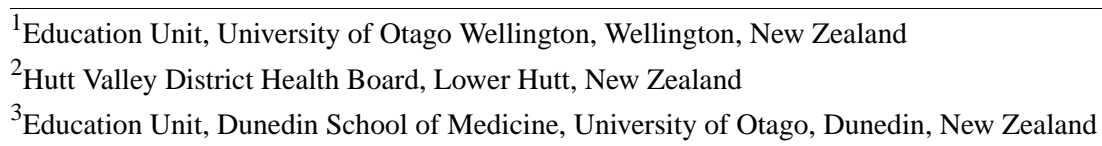

\section{Corresponding Author:}

Tehmina Gladman, $\mathrm{PhD}$

Education Unit

University of Otago Wellington

PO Box 7343

Newtown

Wellington, 6242

New Zealand

Phone: 64049186749

Email: tehmina.gladman@otago.ac.nz

\section{Abstract}

Background: Mobile apps are widely used in health professions, which increases the need for simple methods to determine the quality of apps. In particular, teachers need the ability to curate high-quality mobile apps for student learning.

Objective: This study aims to systematically search for and evaluate the quality of clinical skills mobile apps as learning tools. The quality of apps meeting the specified criteria was evaluated using two measures—-the widely used Mobile App Rating Scale (MARS), which measures general app quality, and the Mobile App Rubric for Learning (MARuL), a recently developed instrument that measures the value of apps for student learning-to assess whether MARuL is more effective than MARS in identifying high-quality apps for learning.

Methods: Two mobile app stores were systematically searched using clinical skills terms commonly found in medical education and apps meeting the criteria identified using an approach based on PRISMA (Preferred Reporting Items for Systematic Reviews and Meta-Analyses) guidelines. A total of 9 apps were identified during the screening process. The apps were rated independently by 2 reviewers using MARS and MARuL.

Results: The intraclass correlation coefficients (ICCs) for the 2 raters using MARS and MARuL were the same (MARS ICC [two-way] $=0.68 ; P<.001$ and MARuL ICC [two-way] $=0.68 ; P<.001$ ). Of the 9 apps, Geeky Medics-OSCE revision (MARS Android=3.74; MARS iOS=3.68; MARuL Android=75; and MARuL iOS=73) and OSCE PASS: Medical Revision (MARS Android=3.79; MARS iOS=3.71; MARuL Android=69; and MARuL iOS=73) scored highly on both measures of app quality and for both Android and iOS. Both measures also showed agreement for the lowest rated app, Patient Education Institute (MARS Android=2.21; MARS iOS=2.11; MARuL Android=18; and MARuL iOS=21.5), which had the lowest scores in all categories except information (MARS) and professional (MARuL) in both operating systems. MARS and MARuL were both able to differentiate between the highest and lowest quality apps; however, MARuL was better able to differentiate apps based on teaching and learning quality.

Conclusions: This systematic search and rating of clinical skills apps for learning found that the quality of apps was highly variable. However, 2 apps-Geeky Medics-OSCE revision and OSCE PASS: Medical Revision—rated highly for both versions and with both quality measures. MARS and MARuL showed similar abilities to differentiate the quality of the 9 apps. However, MARuL's incorporation of teaching and learning elements as part of a multidimensional measure of quality may make it more appropriate for use with apps focused on teaching and learning, whereas MARS's more general rating of quality may be more appropriate for health apps targeting a general health audience. Ratings of the 9 apps by both measures also highlighted the variable quality of clinical skills mobile apps for learning. 
(JMIR Mhealth Uhealth 2021;9(4):e25377) doi: 10.2196/25377

\section{KEYWORDS}

mobile apps; MARS; MARuL; medical education; app review; mobile phone

\section{Introduction}

\section{Background}

Mobile apps are widely used by health care professionals and have been shown to improve documentation, workflows, access to information, and clinical decision support [1]. Apps can be found from web-based vendors (app stores), web-based repositories (app repositories, online communities, and news stories), and peer-reviewed literature [2]. A recently published framework for finding apps [3] recommends peer-reviewed literature as the first source of information on quality apps. This nascent body of literature includes high-quality evaluations of single apps and systematic searches of app stores for apps, often including the appraisal of app quality. There is an emerging literature on systematic app store searches for apps to support clinical care [4-10] and the development of instruments for assessing app quality, such as the Mobile App Rating Scale (MARS) [11]. Although mobile apps are now widely accessible and being implemented in clinical care, the role of mobile apps in medical education is less well evaluated.

Mobile app use for teaching and learning has been an area of exploration since the first smartphones became available, and there has been growing use since then [12]. With this increased use, some studies have aimed to determine the characteristics of mobile apps that best contribute to student learning [12,13]. The app characteristics that users identify as best-promoting self-regulated and deep learning include perceived usefulness, perceived satisfaction, and interactivity [13,14]. Although frameworks for implementing mobile technology in medical education have been proposed [15], the evaluation of mobile technology use among medical students is largely limited to surveys evaluating types of apps used and extent of use [16-19] and barriers and facilitators to the use of mobile devices [20,21]. To date, there have not been many studies to identify or evaluate apps to support medical student learning or any systematic app store searches to identify and evaluate the potential quality of apps aimed at medical students. Such studies would be useful for medical teachers in their role as resource curators [22] so that they can easily compare, identify, and direct students to content-relevant, high-quality apps to support learning. Medical students would also be consumers of such research to find apps that may support self-directed learning. By considering aspects of an app, such as the usefulness of the content being presented, the interactivity of the app in its presentation of content, and its use of methods of learning that increase student satisfaction and interest, such as case-based learning [23], and combining user-centered qualities with technology-centered qualities such as functionality, stability, esthetic appeal, and ease of use [24], we can identify apps that are likely to be effective aids for learning.

We have previously worked with medical students to develop a rubric to evaluate the value of mobile apps to support medical student just-in-time learning [25]. This instrument, the Mobile
App Rubric for Learning (MARuL), can be rapidly and easily used by teachers or students to rate the quality of an app and its potential to be useful for learning. MARuL contains 4 categories: teaching and learning measures $(n=9)$, user-centered measures $(n=7)$, professional measures $(n=3)$, and usability measures $(n=7)$. As mobile apps do not yet seem to be widely endorsed or promoted by medical schools to support learning $[15,26]$, MARuL may offer a tool for the faculty to confidently evaluate the quality of apps to support learning [27].

Although the general quality of any health app can be evaluated with the well-established MARS instrument, apps for medical student learning are a subset of health apps that have a specific purpose requiring additional aspects for evaluation. MARuL, though adapting 9 items from MARS, was designed specifically to measure aspects of an app related to its value for medical student learning [25].

\section{Objectives}

This study reports on the use of MARS and MARuL to evaluate apps designed to help medical students develop clinical skills. Clinical skills are a competency that all medical students need to acquire, requiring complex knowledge, psychomotor skills, and integration skills. Good-quality apps could be a useful learning tool for students to acquire these skills. We define clinical skills as any discrete and observable act within the overall process of patient care [27], and for the purposes of this study, we focus on clinical skills required during a traditional doctor-patient interaction. The apps of interest might support the development of history taking, physical examination skills, and patient explanation, which are often assessed in objective structured clinical examinations (OSCEs).

To extend previous work in developing methods of systematic app store search and app evaluation [28] specifically for apps for medical student learning, we aim to do the following:

- Undertake a systematic search of app stores to identify apps available to support clinical skills development by medical students.

- Evaluate the perceived quality of those apps using MARS and the potential value of those apps for student just-in-time learning of clinical skills using MARuL.

- Compare MARS and MARuL as methods for evaluating perceived quality and value of apps for learning.

\section{Methods}

\section{App Identification}

We performed a systematic app search in the New Zealand Apple iOS App Store and Google Play Store between January 15 and February 1, 2019. Search terms were chosen to focus on apps for teaching and learning in health. Three of the authors (TG, GT, and RG) developed the search terms and inclusion and exclusion criteria through preliminary searches and 
discussion. The final set contained 14 search terms that were searched one at a time (Textbox 1).

Textbox 1. Search terms used in app stores grouped by focus of search term.

\author{
General: \\ - $\quad$ Clinical skills \\ Objective Structured Clinical Examination: \\ - $\quad$ OSCE \\ - Objective Structured Clinical Examination \\ History taking: \\ - Medical history taking \\ - Clinical history taking \\ - Patient history \\ Examinations: \\ - Medical examination \\ - Medical exam \\ - Physical examination \\ - Physical exam \\ - Clinical examination \\ - Clinical exam \\ Explanation: \\ - Planning and explaining \\ - Patient education
}

\section{Eligibility Criteria}

Apps were initially screened during the search by reading the title and description of the app in the app store. Apps were eligible for inclusion in the review if, in the initial screening, they fulfilled the following 6 inclusion criteria: (1) were available in English; (2) included at least one of the keywords (Textbox 1) in the title or description; (3) included an interactive element requiring some form of input (as deliberate practice with active learning is more effective [14] - to be interactive, an app must require students to perform in some way, eg, by filling in a form, answering questions, or interacting with an image by rotation or other means); (4) their target audience included medical students based on a statement in the app description; (5) supported iOS 8 or later and Android version 5 or later (to include devices in the last 5 years that used these systems); (6) were available for both Android and iOS to ensure student accessibility.

Apps were excluded if they failed to meet the inclusion criteria or if they met any of the following exclusion criteria: (1) priced more than NZ \$10 (US \$7) for a monthly subscription or as a one-off price; based on a discussion with GT, student research collaborator, and RG, a local leader in medical education and experienced clinician; this was thought to be a reasonable maximum cost that either a student would spend on themselves or an institution would be willing to spend per user; (2) were reference-only apps (passive with no student input, ie, do not require students to interact beyond basic touchscreen requirements such as page turning or pressing play on a video, eg, textbook apps or apps that contain videos of clinical skills being performed that students watch but do not interact with); (3) designed for staff-only use in formative or summative assessment contexts; (4) complemented other software (not stand alone); and (5) required a log in or sign up to be used $[29,30]$ based on a discussion with GT who noted that requiring an initial signup or registration was a barrier to use for most of her student colleagues. These exclusion criteria were based on potential barriers to students' use or reduced quality of learning for students.

\section{Data Extraction}

A data screening and extraction spreadsheet was developed and refined by 2 researchers (GT and TG) using Airtable [31] before the search. The app name, developer, operating system, reviewer, and whether the app was included or excluded were recorded in the spreadsheet during the initial search and screening of the app store search. Apps were excluded if one of the exclusion criteria was met, and the reason for exclusion was recorded. The iOS store was searched using an iPhone 7 (Apple Inc) and an iPhone 8 using iOS version 12.1.3, and the Google Play Store was searched using 2 Samsung Galaxy J1 Ace phones using Android version 5.1.1.

The app search for the iOS App Store and Google Play Store was completed in parallel but independently by 2 authors (GT 
and TG). GT and TG then jointly reviewed the apps where there was a lack of agreement. Each discrepancy was discussed, and a final decision was made regarding inclusion or exclusion and the grounds for exclusion. The search and screening are reported based on the PRISMA (Preferred Reporting Items for Systematic Reviews and Meta-Analyses) phase 1 guidelines, modified for app stores and app metadata [32].

\section{App Rating}

All included apps were independently rated by 2 reviewers (JM and SG) with MARS [11] and MARuL [25]. The 2 reviewers were chosen because of their relationship to the student experience. One reviewer is a near peer of medical students, and the other reviewer works extensively with web-based learning for medical education to support student learning. Both MARS and MARuL versions include instructions to consider the target audience for the app, and the individual items of each measure use language keeping the target audience in mind.

First, the 2 reviewers met on videoconference to confirm their understanding of each rubric and its submeasures. They then completed a pilot rating on one excluded app and met on videoconference to discuss their scoring on the items and come to an agreement on how to interpret items that they differed on. The reviewers then independently downloaded and reviewed the included apps in iOS (iPhone 6 Plus and iPhone 6s) and Android (Samsung Galaxy J1 Ace) between November 10 and December 9, 2019. App reviews were completed using the MARS and MARuL in a web-based form (Qualtrics), with data exported to an Excel spreadsheet (Microsoft Office, version 16.40,20081000). The reviewers interacted with each app to fully explore its features before completing the MARS and MARuL. Both category and overall scores on MARS and MARuL for each app were calculated for each reviewer. To measure interrater reliability for MARS and MARuL, intraclass correlation coefficient (ICC) estimates were calculated with their 95\% CIs in RStudio [33] based on a single-rating, consistency, two-way mixed effects model [34].

MARS comprises four categories of perceived app quality-engagement, functionality, esthetics, and information-and 1 category of subjective quality. Each category score is the mean of the items, rated on a 5-point Likert-type scale (from 1=inadequate to 5=excellent) within its category. The overall quality score was calculated by taking the mean of the 4 app quality category scores, with a final score ranging from 0 to 5 [11].
MARuL is composed of four categories, each of which receives a score. The category scores are summed together to reach an overall value for the learning score. The MARuL category score is calculated by adding the rating for each item on a 5-point Likert-type scale $(0=$ does not fulfill the item requirements, $1=$ poorly fulfills the requirements, $2=$ somewhat fulfills the requirements, $3=$ mostly fulfills the requirements, and $4=$ fully meets the requirements) within each category to reach a total score for that category (teaching and learning $=36$, user-centered $=28$, professional measures $=12$, and usability $=28$ ). Summing the categories gives the user an overall score of 104 . Apps are then categorized by their scoring range $(<50=$ not at all valuable, 51-69=potentially valuable, and $>69=$ probably valuable) [25].

\section{Results}

\section{App Store Search}

A total of $1291 \mathrm{iOS}$ apps and 4193 Android apps were screened in the iOS App Store and Google Play Store, respectively. Following the app title and description screening, 1210 iOS apps and 4087 Android apps were excluded. Despite using the same search terms, sometimes discrepancies in the results from the search carried out by the 2 reviewers were seen, such as some apps only being found by one reviewer. Only the apps that were found by both reviewers were included in the final sample. We made this decision as our goal for this study was to rate commonly found apps available in both iOS and Android app stores. If the same apps appeared in a search by both a student and staff member, it was felt that they would be commonly located despite any search optimization in use. The two main reasons for exclusion of Android apps were that no keywords were found within the title or description (1897/4087, $46.4 \%$ ) or that they were only found by one of the 2 researchers $(1599 / 4087,39.1 \%)$. The two main reasons for exclusion of iOS apps were no keywords in the title or description (890/1210, $73.6 \%$ ), followed by a price greater than NZD \$10 (US \$7) as a one-off or recurring cost (129/1210, 10.7\%). For iOS, 81 apps from the 14 search terms were identified, 35 of which were unique apps. For Android apps, a total of 106 apps were identified, of which 29 were unique. Of the 35 unique iOS apps and 29 unique Android apps, 9 apps were found on both iOS App Store and Google Play Store for inclusion. A search of the Apple Store in the United States using the website fnd.io [35] did not find any further apps that were also available in the international Google Play Store. Figure 1 shows the search and screening process. 
Figure 1. Flowchart for the identification of the Google Play Store and iOS App Store clinical skills apps. MARS: Mobile App Rating Scale; MARuL: Mobile App Rubric for Learning. OSCE: objective structured clinical examinations.

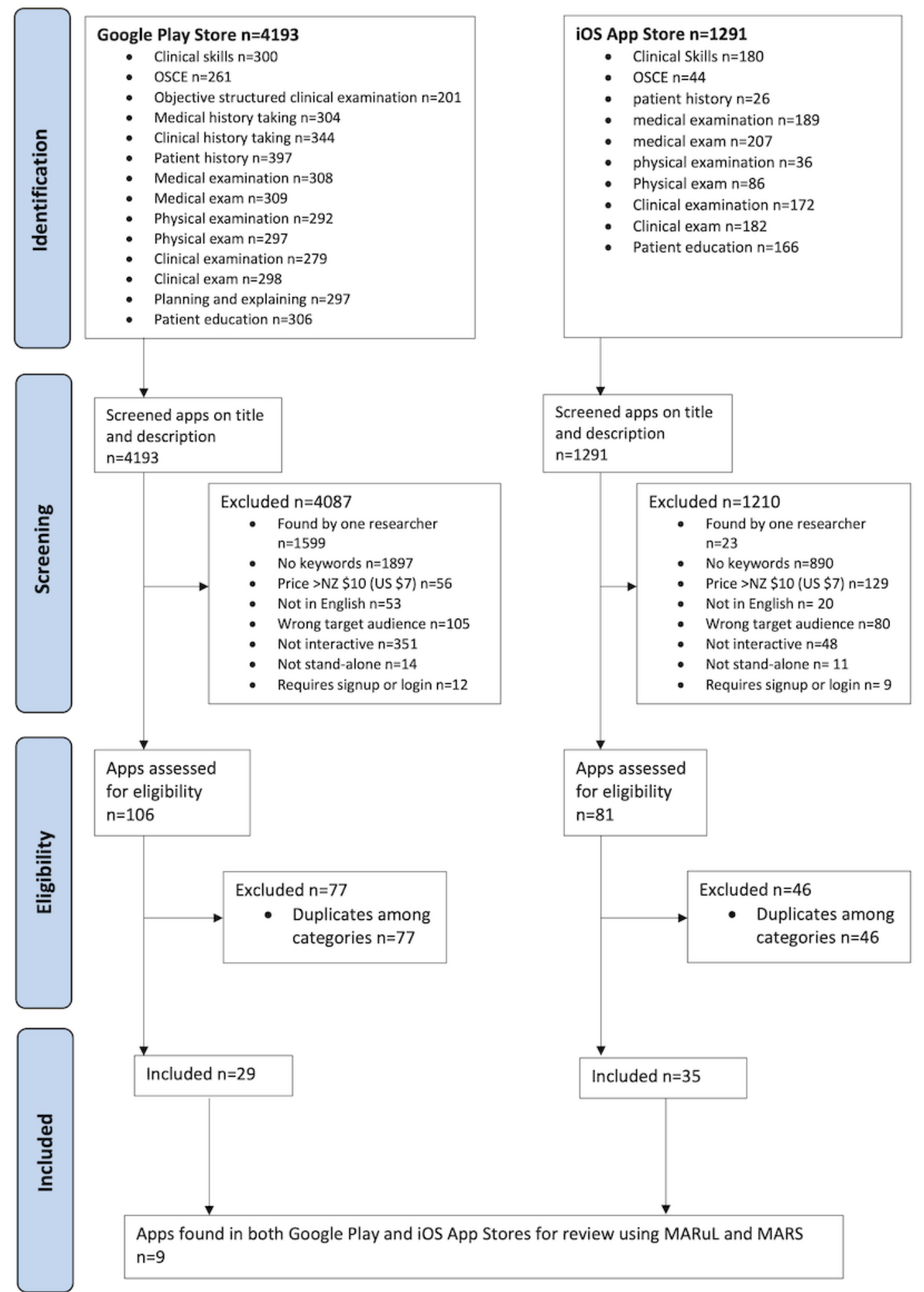

\section{App Characteristics}

The characteristics of the apps are summarized in Table 1 . The apps ranged in size from 2.7 to $229.2 \mathrm{MB}$. All apps were free to download except OSCE PASS: Medical Revision, which cost
NZD \$10 (US \$7). Three of the apps, Geeky Medics-OSCE revision; InSimu: The Patient Simulator; and Resuscitation!, had in-app purchases available for additional content. Of the 9 apps, 7 apps were stated to be for medical students and 5 apps specifically focused on clinical skills for OSCE practice. 
Table 1. Characteristics of the 9 included apps.

\begin{tabular}{|c|c|c|c|c|c|}
\hline App name & Developer & App version & Cost & App size (MB) & Description \\
\hline $\begin{array}{l}\text { CardioSmart; Heart Ex- } \\
\text { plorer }\end{array}$ & $\begin{array}{l}\text { American College of } \\
\text { Cardiology }\end{array}$ & $\begin{array}{l}3.0 \text { (iOS); } 2.3 \\
\text { (Android) }\end{array}$ & Free & 229.2 & $\begin{array}{l}\text { Interactive 3D heart anatomy } \\
\text { and educational pathology } \\
\text { videos }\end{array}$ \\
\hline $\begin{array}{l}\text { Geeky Medics-OSCE } \\
\text { revision }\end{array}$ & Geeky Medics LTD & $\begin{array}{l}2.81 \text { (iOS); } 2.46 \\
\text { (Android) }\end{array}$ & $\begin{array}{l}\text { Free; in-app purchases up } \\
\text { to NZ } \$ 18.99 \text { (US } \$ 13.41 \text { ) } \\
\text { on iOS and NZ } \$ 29.99 \text { (US } \\
\$ 21.18 \text { ) on Android }\end{array}$ & 76.6 & $\begin{array}{l}\text { OSCE guides for medical stu- } \\
\text { dents }\end{array}$ \\
\hline $\begin{array}{l}\text { InSimu-The Patient } \\
\text { Simulator (iOS); In- } \\
\text { Simu-Diagnose Virtual } \\
\text { Clinical Cases (Android) }\end{array}$ & InSimu & $\begin{array}{l}1.7 .7(\mathrm{iOS}) ; 1.8 .7 \\
\text { (Android) }\end{array}$ & $\begin{array}{l}\text { Free; in-app purchases up } \\
\text { to NZ } \$ 499.99 \text { (US } \\
\$ 353.09 \text { ) for lifetime ac- } \\
\text { cess }\end{array}$ & 51.8 & $\begin{array}{l}\text { Virtual clinic environment or } \\
\text { simulation, work-through di- } \\
\text { agnosis }\end{array}$ \\
\hline $\begin{array}{l}\text { OSCE PASS: Medical } \\
\text { Revision }\end{array}$ & Entremed Ltd & $\begin{array}{l}1.1 \text { (iOS); } 1.0 \\
\text { (Android) }\end{array}$ & NZ \$10 (US \$7) & $\begin{array}{l}8.3 \text { (iOS); } 3.79 \\
\text { (Android) }\end{array}$ & $\begin{array}{l}\text { Written guides and video } \\
\text { demonstrations for clinical } \\
\text { skills }\end{array}$ \\
\hline $\begin{array}{l}\text { OSCE Revision for Med- } \\
\text { ical Students (iOS); } \\
\text { OSCE Revision (An- } \\
\text { droid) }\end{array}$ & Matthew Roche & $\begin{array}{l}1.2 .1(\mathrm{iOS}) ; 1.1 .5 \\
\text { (Android) }\end{array}$ & Free & 10.2 & $\begin{array}{l}\text { OSCE revision guides with } \\
\text { test function }\end{array}$ \\
\hline OSCEr & $\begin{array}{l}\text { Ahmad Alhashemi } \\
\text { (iOS); Essentials of } \\
\text { clinical examination } \\
\text { (Android) }\end{array}$ & 1.0 & Free & 22.2 & $\begin{array}{l}\text { Guides for clinical skills with } \\
\text { test and practice options }\end{array}$ \\
\hline $\begin{array}{l}\text { Pocket PEx: Physical } \\
\text { Exam Aid (iOS); Pocket } \\
\text { PEx (Android) }\end{array}$ & $\begin{array}{l}\text { Charles Goldberg } \\
\text { (iOS); MedEd Apps } \\
\text { (Android) }\end{array}$ & 3.1 & Free & 2.9 & $\begin{array}{l}\text { Interactive checklists for } \\
\text { physical examination }\end{array}$ \\
\hline Resuscitation! & EM Gladiators LLC & $\begin{array}{l}2.8 \text { (iOS); } 2.0 \\
\text { (Android) }\end{array}$ & $\begin{array}{l}\text { Free; in-app purchases up } \\
\text { to NZ } \$ 16.99 \text { (US } \$ 11.99 \text { ) }\end{array}$ & 82.7 & $\begin{array}{l}\text { Virtual patient simulator, } \\
\text { work-through diagnosis }\end{array}$ \\
\hline $\begin{array}{l}\text { Patient Education Insti- } \\
\text { tute }\end{array}$ & $\begin{array}{l}\text { Olaf Breukhoven (iOS); } \\
\text { The Patient Education } \\
\text { Institute (Android) }\end{array}$ & $\begin{array}{l}1.2 .3(\mathrm{iOS}) ; 1.2 .2 \\
\text { (Android) }\end{array}$ & Free & 2.7 & Medical illustrations \\
\hline
\end{tabular}

${ }^{\mathrm{a} O S C E}$ : objective structured clinical examination.

\section{App Rating}

The 9 apps reviewed by the 2 researchers were CardioSmart Heart Explorer; Geeky Medics-OSCE revision; InSimu-The Patient Simulator; OSCE Revision; OSCEr; Pocket PEx:
Physical Exam Aid; OSCE PASS: Medical Revision; Patient Education Institute; and Resuscitation! ICC scores for MARuL was ICC (two-way)=0.68 $(P<.001)$ and for MARS was ICC (two-way) $=0.68(P<.001)$, indicating moderate reliability (Table 2) [34].

Table 2. Interrater reliability scores for the Mobile App Rubric for Learning and Mobile App Rating Scale.

\begin{tabular}{lllll}
\hline Rating measures & Intraclass correlation & $95 \%$ CI & \multicolumn{2}{c}{$F$ test with true value 0} \\
& & & $F$ test $(d f)$ & $P$ value \\
\hline MARS $^{\text {a }}$ & 0.677 & $0.618-0.729$ & $5.2(367)$ & $<.001$ \\
MARuL $^{\text {b }}$ & 0.676 & $0.621-0.725$ & $5.18(415)$ & $<.001$ \\
\hline
\end{tabular}

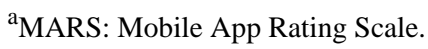

bMARuL: Mobile App Rubric for Learning.

The total app quality mean scores from the MARS evaluation ranged from 2.11 to 3.71 on the $9 \mathrm{iOS}$ apps and 2.21 to 3.79 on the 9 Android apps (Table 3), with lowest scores generally occurring in the engagement and information categories. OSCE
PASS: Medical Revision (iOS=3.71; Android=3.79), Geeky Medics-OSCE revision (iOS=3.68; Android=3.74), and CardioSmart Heart Explorer (iOS=3.53; Android=3.53) were the top-scoring apps on iOS and Android. 
Table 3. Average Mobile App Rating Scale scores from the 2 raters for the 9 apps tested.

\begin{tabular}{|c|c|c|c|c|c|c|}
\hline Operating system and app name & Total & Engagement & Functionality & Aesthetics & Information & Subjective quality \\
\hline \multicolumn{7}{|l|}{ Android } \\
\hline OSCE $^{\mathrm{a}}$ PASS: Medical Revision & 3.79 & 3.60 & 4.63 & 3.83 & 3.43 & 3.88 \\
\hline Geeky Medics-OSCE revision & 3.74 & 3.70 & 4.38 & 4.00 & 3.29 & 3.88 \\
\hline CardioSmart Heart Explorer & 3.53 & 3.10 & 4.38 & 4.33 & 3.00 & 2.00 \\
\hline Resuscitation! & 3.45 & 3.60 & 4.38 & 3.50 & 2.79 & 3.63 \\
\hline OSCEr & 3.24 & 2.90 & 4.25 & 3.67 & 2.71 & 2.00 \\
\hline InSimu-The Patient Simulator & 3.03 & 3.20 & 3.63 & 3.17 & 2.50 & 1.88 \\
\hline Pocket PEx: Physical Exam Aid & 2.76 & 2.10 & 4.00 & 2.67 & 2.57 & 1.88 \\
\hline OSCE Revision for Medical Students & 2.39 & 2.00 & 2.75 & 3.00 & 2.21 & 1.63 \\
\hline Patient Education Institute & 2.21 & 1.60 & 2.75 & 2.17 & 2.36 & 1.00 \\
\hline \multicolumn{7}{|l|}{ iOS } \\
\hline OSCE PASS: Medical Revision & 3.71 & 3.40 & 4.50 & 4.00 & 3.36 & 3.88 \\
\hline Geeky Medics-OSCE revision & 3.68 & 3.10 & 4.75 & 4.17 & 3.29 & 3.75 \\
\hline CardioSmart Heart Explorer & 3.53 & 3.00 & 4.25 & 4.33 & 3.14 & 2.38 \\
\hline Resuscitation! & 3.50 & 3.60 & 4.50 & 3.67 & 2.79 & 3.63 \\
\hline OSCEr & 3.16 & 2.90 & 4.25 & 3.50 & 2.57 & 2.13 \\
\hline Pocket PEx: Physical Exam Aid & 2.84 & 2.10 & 4.13 & 2.67 & 2.71 & 1.75 \\
\hline InSimu—The Patient Simulator & 2.76 & 2.80 & 3.38 & 3.33 & 2.14 & 1.75 \\
\hline OSCE Revision for Medical Students & 2.66 & 2.70 & 3.13 & 3.00 & 2.21 & 1.88 \\
\hline Patient Education Institute & 2.11 & 1.50 & 2.63 & 2.00 & 2.29 & 1.00 \\
\hline
\end{tabular}

${ }^{\mathrm{a} O S C E}$ : objective structured clinical examination.

The MARuL overall app scores ranged from 21.5 to 73.0 for the 9 iOS apps and 18.0 to 75.0 for the 9 Android apps. Two apps, Geeky Medics-OSCE revision and OSCE PASS: Medical Revision, scored as probably valuable in both $\mathrm{IOS}$ and Android, and 1 app-Resuscitation! — as potentially valuable in both iOS and Android (Table 4). CardioSmart Heart Explorer scored at the low end of the range for potentially valuable in Android only. The remaining apps had a MARuL score of less than 50 or not at all valuable. 
Table 4. Average Mobile App Rubric for Learning scores from the 2 raters for the 9 apps tested.

\begin{tabular}{|c|c|c|c|c|c|}
\hline Operating system and app name & $\begin{array}{l}\text { Total score } \\
\text { out of } 104\end{array}$ & $\begin{array}{l}\text { User-centered score } \\
\text { out of } 28\end{array}$ & $\begin{array}{l}\text { Teaching and learning } \\
\text { score out of } 36\end{array}$ & $\begin{array}{l}\text { Professional score } \\
\text { out of } 12\end{array}$ & $\begin{array}{l}\text { Usability score } \\
\text { out of } 28\end{array}$ \\
\hline \multicolumn{6}{|l|}{ Android } \\
\hline Geeky Medics-OSCE ${ }^{\mathrm{a}}$ revision & 75 & 20 & 24 & 8.5 & 22.5 \\
\hline OSCE PASS: Medical Revision & 69 & 20 & 24 & 5.5 & 19.5 \\
\hline Resuscitation! & 65 & 19 & 21 & 5 & 20 \\
\hline CardioSmart Heart Explorer & 54.5 & 11 & 12.5 & 9.5 & 21.5 \\
\hline OSCE Revision for Medical Students & 50 & 8.5 & 19.5 & 6.5 & 15.5 \\
\hline OSCEr & 47.5 & 9 & 15 & 6 & 17.5 \\
\hline Pocket PEx: Physical Exam Aid & 46 & 7.5 & 14.5 & 8.5 & 15.5 \\
\hline InSimu—The Patient Simulator & 40.5 & 8.5 & 8.5 & 5.5 & 18 \\
\hline Patient Education Institute & 18 & 1 & 2 & 5 & 10 \\
\hline \multicolumn{6}{|l|}{ iOS } \\
\hline Geeky Medics-OSCE revision & 73 & 19.5 & 24 & 8.5 & 21 \\
\hline OSCE PASS: Medical Revision & 73 & 19.5 & 25.5 & 8 & 20 \\
\hline Resuscitation! & 66 & 18.5 & 22 & 5.5 & 20 \\
\hline CardioSmart Heart Explorer & 49.5 & 10.5 & 10.5 & 10 & 18.5 \\
\hline Pocket PEx: Physical Exam Aid & 49 & 8.5 & 16 & 8 & 16.5 \\
\hline OSCEr & 48 & 9 & 16 & 6 & 17 \\
\hline InSimu—-The Patient Simulator & 45 & 9 & 8.5 & 7.5 & 20 \\
\hline OSCE Revision for Medical Students & 39.5 & 5.5 & 14 & 6.5 & 13.5 \\
\hline Patient Education Institute & 21.5 & 1.5 & 2 & 6 & 12 \\
\hline
\end{tabular}

${ }^{\mathrm{a} O S C E}$ : objective structured clinical examination.

\section{Discussion}

\section{Principal Findings}

This systematic app store search of the iOS App Store and Google Play Store for apps supporting the development of clinical skills required in the doctor-patient consultation in medical students resulted in the inclusion of 9 relevant apps. The evaluation of the 9 apps - using MARS [11] and MARuL [25] — found only 2 apps that scored highly in fulfilling the quality criteria across both measures of perceived quality for both mobile operating systems, Geeky Medics-OSCE revision and OSCE PASS: Medical Revision. However, each operating system and quality measure identified 3 apps that scored highly in fulfilling the criteria. The top 3 apps as rated by MARS were OSCE PASS: Medical Revision, Geeky Medics-OSCE revision, and CardioSmart Heart Explorer. For MARuL, Geeky Medics-OSCE revision, OSCE PASS: Medical Revision, and Resuscitation! were the top-scoring apps.

MARS and MARuL were designed to measure the perceived quality of apps for different purposes. Although MARS was developed as a method for measuring the perceived quality of a health mobile app for general use purposes [11], MARuL was specifically developed as a measure of the perceived value of a health education app to support student learning [25]. Both measures differentiated between apps of varying quality, as shown by the similarity of their top-ranked apps and the consistency with which they categorized the lowest ranked app, Patient Education Institute, across most of their categories. The similar results for the ranking of apps across the 2 measures indicate that both measures are helpful in characterizing the perceived value or quality of mobile health apps. However, having a category specifically designed to measure teaching and learning allows teachers to use MARuL to measure perceived value for student learning. For example, although CardioSmart Heart Explorer was the third highest rated app using MARS, MARuL rated it at the low end of the category potentially valuable on Android devices (54.5), and the iOS version had an overall score of $<50$ (49.5). Scrutiny of the individual categories of MARuL reveals that CardioSmart Heart Explorer had the third lowest score for teaching and learning in both iOS (10.5) and Android (12.5).

After review using both MARS and MARuL, it was found that the quality of the 9 apps was highly variable. For example, in the MARS evaluations, apps tended to score the highest in the functionality category, followed by esthetics. The scores for engagement and information were the lowest. The engagement category of MARS considers whether the app is fun, interesting, customizable, interactive, and well-targeted to the audience. Similarly, the user-centered category of MARuL considers aspects of the app, such as satisfaction, user experience, and engagement. Of the 9 apps, 6 scored less than half of the 
possible points in this category. It is concerning that apps consistently scored low in this category, as interest and enjoyment have been found to be strong influencers on students' persistence of learning [36-38].

One of the criteria for inclusion of apps in our review was the presence of interactivity within the app. Interactivity was evaluated in both MARS and MARuL. Interactivity increases engagement and may stimulate better learning of a topic [14]. Although all the apps reviewed were interactive, the degree of interactivity varied among apps. For example, the app Pocket PEx: Physical Exam Aid had minimal interactivity with checkboxes for each component of a physical exam, whereas the app InSimu had a comprehensive diagnostic scenario with interactivity for each step of the diagnostic process.

Both MARS and MARuL contain a category that includes items on information quality and credibility. Apps performed poorly in this category with only one app, Pocket PEx: Physical Exam Aid, containing easy-to-find references for information. No references were provided for the other apps. This poses a challenge for all types of health apps because of the importance of accurate and evidence-based information [39-41].

As noted earlier, MARuL has a category for the teaching and learning aspects of an app. It includes items on app purpose, pedagogy, capacity to generate learning, quantity of information, relevance to study or course, instructional features, user interactivity, feedback, and efficiency. The highest scoring apps in the teaching and learning category were Geeky Medics-OSCE revision, OSCE PASS, and Resuscitation!, which were also the top-scoring apps overall. Although the teaching and learning category has the highest weighting in the MARuL overall score, and the scoring trend for most apps across the other categories was similar to the teaching and learning category, taking a multidimensional approach to evaluation is important because of the interdependence of the dimensions in measuring value [24]. These findings of variable quality of clinical skills learning apps are consistent with findings from app reviews for patient-centered health-related apps [10,42] and are likely because of the poorly regulated market for mobile health apps.

\section{Limitations}

The app store search was conducted in the New Zealand iOS App Store and Google Play Store. Although this could limit the generalizability of our findings to other countries with different app stores, it should be noted that the Google Play Store is international and a search of the iOS store in the United States using fnd.io [35] did not find any new apps that were included in the Google Play Store. This limitation has been discussed in other app reviews. However, this study specifically focuses on New Zealand medical students; therefore, generalizability is not an immediate concern [43]. The app stores were searched in early 2019. As the rate of change in the app stores is high, it is possible that the apps we originally excluded have now changed enough to be included and other apps may have been removed since the search and review were conducted. The constantly changing nature of apps and their availability in app stores have also been discussed in previous reviews [44,45]. As such, it may prove challenging to keep an up-to-date list of good-quality apps for students to use. The interrater reliability of our MARS and MARuL scores was moderate, which was slightly lower than that described in the MARS and similar to the MARuL development. Although higher reliability might change scoring somewhat, it is unlikely to change our findings, as each individual reviewer identified the same top 3 apps, albeit in a different order, for both MARS and MARuL.

\section{Next Steps}

The results across the 2 measures of app quality indicate the potential convergent and discriminant validity of raters' perceptions across MARS and MARuL. Further research to develop the construct validity of these 2 measures by using student outcome data with regard to highly rated apps will help to confirm their usefulness in their respective areas of focus.

\section{Conclusions}

This systematic search for and evaluation of clinical skills mobile apps for perceived general quality and value for learning has highlighted the importance of using a fit-for-purpose measure of quality or value of mobile apps. The findings suggest that both MARS and MARuL instruments are useful and somewhat complementary. This study also highlights the variable quality of health-related education apps, likely because of the lack of regulation of health apps, in the iOS App Store and Google Play Store. However, Geeky Medics-OSCE revision and OSCE PASS are examples of how good practice in the development of apps can lead to quality apps for learning.

\section{Acknowledgments}

This work was supported by a grant from the Otago Medical School Medical Education Research Fund. The authors would like to thank Michael Fauchelle from the University of Otago Wellington Medical and Health Sciences Library for his assistance with the initial literature search.

\section{Authors' Contributions}

TG developed the initial research question and methodology, completed the app store searches, analyzed the data, and drafted the manuscript. GT assisted with the development of the methodology, reviewed the literature, completed the app store searches, assisted with writing the first draft, and edited the manuscript. SG assisted with the development of the methodology, reviewed the apps using MARS and MARuL, and edited the manuscript. JM reviewed the apps using MARS and MARuL and edited the manuscript. RG assisted with the development of the methodology and edited the manuscript. 


\section{Conflicts of Interest}

None declared.

\section{References}

1. Mickan S, Tilson JK, Atherton H, Roberts NW, Heneghan C. Evidence of effectiveness of health care professionals using handheld computers: a scoping review of systematic reviews. J Med Internet Res 2013 Oct 28;15(10):e212 [FREE Full text] [doi: 10.2196/jmir.2530] [Medline: 24165786]

2. Paglialonga A, Lugo A, Santoro E. An overview on the emerging area of identification, characterization, and assessment of health apps. J Biomed Inform 2018 Jul;83:97-102 [FREE Full text] [doi: 10.1016/j.jbi.2018.05.017] [Medline: 29852318]

3. Scott IA, Scuffham P, Gupta D, Harch TM, Borchi J, Richards B. Going digital: a narrative overview of the effects, quality and utility of mobile apps in chronic disease self-management. Aust Health Rev 2018 Nov;44(1):62-82. [doi: 10.1071/AH18064] [Medline: 30419185]

4. Mosa AS, Yoo I, Sheets L. A systematic review of healthcare applications for smartphones. BMC Med Inform Decis Mak 2012 Jul 10;12:67 [FREE Full text] [doi: 10.1186/1472-6947-12-67] [Medline: 22781312]

5. Sucala M, Cuijpers P, Muench F, Cardo R, Soflau R, Dobrean A, et al. Anxiety: there is an app for that. A systematic review of anxiety apps. Depress Anxiety 2017 Jun;34(6):518-525. [doi: 10.1002/da.22654] [Medline: 28504859]

6. Meghani SH, MacKenzie MA, Morgan B, Kang Y, Wasim A, Sayani S. Clinician-targeted mobile apps in palliative care: a systematic review. J Palliat Med 2017 Oct;20(10):1139-1147. [doi: 10.1089/jpm.2017.0070] [Medline: 28557549]

7. Kim BY, Sharafoddini A, Tran N, Wen EY, Lee J. Consumer mobile apps for potential drug-drug interaction check: systematic review and content analysis using the Mobile App Rating Scale (MARS). JMIR Mhealth Uhealth 2018 Mar 28;6(3):e74 [FREE Full text] [doi: 10.2196/mhealth.8613] [Medline: 29592848]

8. Nicholas J, Larsen ME, Proudfoot J, Christensen H. Mobile apps for bipolar disorder: a systematic review of features and content quality. J Med Internet Res 2015 Aug 17;17(8):e198 [FREE Full text] [doi: 10.2196/jmir.4581] [Medline: 26283290]

9. Alessa T, Abdi S, Hawley MS, de Witte L. Mobile apps to support the self-management of hypertension: systematic review of effectiveness, usability, and user satisfaction. JMIR Mhealth Uhealth 2018 Jul 23;6(7):e10723 [FREE Full text] [doi: 10.2196/10723] [Medline: 30037787]

10. Grainger R, Townsley H, White B, Langlotz T, Taylor WJ. Apps for people with rheumatoid arthritis to monitor their disease activity: a review of apps for best practice and quality. JMIR Mhealth Uhealth 2017 Mar 21;5(2):e7. [doi: 10.2196/mhealth.6956] [Medline: 28223263]

11. Stoyanov SR, Hides L, Kavanagh DJ, Zelenko O, Tjondronegoro D, Mani M. Mobile app rating scale: a new tool for assessing the quality of health mobile apps. JMIR Mhealth Uhealth 2015 Mar 11;3(1):e27 [FREE Full text] [doi: 10.2196/mhealth.3422] [Medline: 25760773]

12. Jonas-Dwyer DR, Clark C, Celenza A, Siddiqui ZS. Evaluating apps for learning and teaching. Int J Emerg Technol Learn 2012 Feb 29;7(1):54-57. [doi: 10.3991/ijet.v7i1.1901]

13. Chuchu T, Ndoro T. An examination of the determinants of the adoption of mobile applications as learning tools for higher education students. Int J Interact Mob Technol 2019 Mar 25;13(03):53-67. [doi: 10.3991/ijim.v13i03.10195]

14. Liaw SS, Huang HM. Perceived satisfaction, perceived usefulness and interactive learning environments as predictors to self-regulation in e-learning environments. Comput Educ 2013 Jan;60(1):14-24. [doi: 10.1016/j.compedu.2012.07.015]

15. Masters K, Ellaway RH, Topps D, Archibald D, Hogue RJ. Mobile technologies in medical education: AMEE Guide No. 105. Med Teach 2016 Jun;38(6):537-549. [doi: 10.3109/0142159X.2016.1141190] [Medline: 27010681]

16. Boruff JT, Storie D. Mobile devices in medicine: a survey of how medical students, residents, and faculty use smartphones and other mobile devices to find information. J Med Libr Assoc 2014 Jan;102(1):22-30 [FREE Full text] [doi: 10.3163/1536-5050.102.1.006] [Medline: 24415916]

17. Payne KF, Wharrad H, Watts K. Smartphone and medical related App use among medical students and junior doctors in the United Kingdom (UK): a regional survey. BMC Med Inform Decis Mak 2012;12:121 [FREE Full text] [doi: 10.1186/1472-6947-12-121] [Medline: 23110712]

18. Snashall E, Hindocha S. The use of smartphone applications in medical education. Open Medicine J 2016 Dec 27;3(1):322-327. [doi: 10.2174/1874220301603010322]

19. Wallace S, Clark M, White J. 'It's on my iPhone': attitudes to the use of mobile computing devices in medical education, a mixed-methods study. BMJ Open 2012;2(4):e001099 [FREE Full text] [doi: 10.1136/bmjopen-2012-001099] [Medline: 22923627]

20. Mackay BJ, Anderson J, Harding T. Mobile technology in clinical teaching. Nurse Educ Pract 2017 Jan;22:1-6. [doi: 10.1016/j.nepr.2016.11.001] [Medline: 27871040]

21. Dimond R, Bullock A, Lovatt J, Stacey M. Mobile learning devices in the workplace: 'as much a part of the junior doctors' kit as a stethoscope'? BMC Med Educ 2016 Aug 17;16(1):207 [ [FREE Full text] [doi: 10.1186/s12909-016-0732-z] [Medline: 27530343]

22. Harden RM, Lilley P. The Eight Roles of the Medical Teacher. Edinburgh: Elsevier; 2018:1-328. 
23. Thistlethwaite JE, Davies D, Ekeocha S, Kidd JM, MacDougall C, Matthews P, et al. The effectiveness of case-based learning in health professional education. A BEME systematic review: BEME Guide No. 23. Med Teach 2012;34(6):421-444. [doi: 10.3109/0142159X.2012.680939] [Medline: 22578051]

24. Lee JS, Kim SW. Validation of a tool evaluating educational apps for smart education. J Educ Comput Res 2015 Mar 26;52(3):435-450. [doi: 10.1177/0735633115571923]

25. Gladman T, Tylee G, Gallagher S, Mair J, Rennie S, Grainger R. A tool for rating the value of health education mobile apps to enhance student learning (MARuL): development and usability study. JMIR Mhealth Uhealth 2020 Jul 31;8(7):e18015 [FREE Full text] [doi: 10.2196/18015] [Medline: $\underline{\text { 32735228] }}$

26. Snow CE, Torous J, Gordon-Elliott JS, Penzner JB, Meyer F, Boland R. Use of electronic resources for psychiatry clerkship learning: a medical student survey. Acad Psychiatry 2017 Oct;41(5):656-660. [doi: 10.1007/s40596-016-0647-3] [Medline: 27995539]

27. Task Force on the Clinical Skills Education of Medical Students. Recommendations for clinical skills curricula for undergraduate medical education. Association of American Medical Colleges. 2005. URL: https://store.aamc.org/ downloadable/download/sample/sample id/174/ [accessed 2021-03-30]

28. Grainger R, Devan H, Sangelaji B, Hay-Smith J. Issues in reporting of systematic review methods in health app-focused reviews: a scoping review. Health Informatics J 2020 Dec;26(4):2930-2945 [FREE Full text] [doi:

10.1177/1460458220952917] [Medline: 32914696]

29. Do we really need App logins? Apptimize. 2015. URL: https://apptimize.com/blog/2015/04/do-we-really-need-app-logins/ [accessed 2021-02-01]

30. Brandall B. First-time use: how to reduce the initial friction of app usage. Usability Geek. URL: https://usabilitygeek.com/ first-time-use-how-to-reduce-initial-friction-of-app-usage/ [accessed 2021-02-01]

31. Liu H, Ofstad A, Nicholas E. Airtable. 2019. URL: https://airtable.com/ [accessed 2019-03-30]

32. Moher D, Liberati A, Tetzlaff J, Altman DG, PRISMA Group. Preferred reporting items for systematic reviews and meta-analyses: the PRISMA statement. Br Med J 2009 Jul 21;339:b2535 [FREE Full text] [doi: 10.1136/bmj.b2535] [Medline: 19622551$]$

33. RStudio Team. RStudio: integrated development environment for R. 2019. URL: https://www.rstudio.com/products/rstudio/ [accessed 2020-03-30]

34. Koo TK, Li MY. A guideline of selecting and reporting intraclass correlation coefficients for reliability research. J Chiropr Med 2016 Jun;15(2):155-163 [FREE Full text] [doi: 10.1016/j.jcm.2016.02.012] [Medline: 27330520]

35. Mack J, Mack R. Fnd: experience the App store and iTunes anywhere. 2021. URL: https://fnd.io/ [accessed 2021-01-27]

36. Awan O, Dey C, Salts H, Brian J, Fotos J, Royston E, et al. Making learning fun: gaming in radiology education. Acad Radiol 2019 Aug;26(8):1127-1136. [doi: 10.1016/j.acra.2019.02.020] [Medline: 31005406$]$

37. Rotgans JI, Schmidt HG. The role of interest in learning: knowledge acquisition at the intersection of situational and individual interest. In: O'Keefe P, Harackiewicz J, editors. The Science of Interest. Switzerland: Springer; 2017:69-93.

38. Thoman DB, Sansone C, Geerling D. The dynamic nature of interest: embedding interest within self-regulation. In: O'Keefe P, Harackiewicz J, editors. The Science of Interest. Switzerland: Springer; 2017:27-47.

39. Hurst EJ. Evaluating health and wellness mobile applications. J Hosp Librariansh 2018 Jul 17;18(3):266-278. [doi: 10.1080/15323269.2018.1472928]

40. Böhme C, von Osthoff MB, Frey K, Hübner J. Development of a rating tool for mobile cancer apps: information analysis and formal and content-related evaluation of selected cancer apps. J Cancer Educ 2019 Feb;34(1):105-110. [doi: 10.1007/s13187-017-1273-9] [Medline: 28819928]

41. Fiore P. How to evaluate mobile health applications: a scoping review. Stud Health Technol Inform 2017;234:109-114. [Medline: 28186025]

42. Devan H, Farmery D, Peebles L, Grainger R. Evaluation of self-management support functions in apps for people with persistent pain: systematic review. JMIR Mhealth Uhealth 2019 Feb 12;7(2):e13080 [FREE Full text] [doi: 10.2196/13080] [Medline: 30747715]

43. Jamaladin H, van de Belt TH, Luijpers LC, de Graaff FR, Bredie SJ, Roeleveld N, et al. Mobile apps for blood pressure monitoring: systematic search in app stores and content analysis. JMIR Mhealth Uhealth 2018 Nov 14;6(11):e187 [FREE Full text] [doi: 10.2196/mhealth.9888] [Medline: 30429116]

44. LeBeau K, Huey LG, Hart M. Assessing the quality of mobile apps used by occupational therapists: evaluation using the user version of the mobile application rating scale. JMIR Mhealth Uhealth 2019 May 01;7(5):e13019 [FREE Full text] [doi: 10.2196/13019] [Medline: 31066712]

45. Virani A, Duffett-Leger L, Letourneau N. Parenting apps review: in search of good quality apps. Mhealth 2019;5:44 [FREE Full text] [doi: 10.21037/mhealth.2019.08.10] [Medline: $\underline{31620471]}$

\section{Abbreviations \\ ICC: intraclass correlation coefficient \\ MARS: Mobile App Rating Scale}


MARuL: Mobile App Rubric for Learning

OSCE: objective structured clinical examination

PRISMA: Preferred Reporting Items for Systematic Reviews and Meta-Analyses

Edited by L Buis; submitted 29.10.20; peer-reviewed by N Moore, M Fajardo; comments to author 15.12.20; revised version received 01.02.21; accepted 18.03.21; published 23.04.21

Please cite as:

Gladman T, Tylee G, Gallagher S, Mair J, Grainger R

Measuring the Quality of Clinical Skills Mobile Apps for Student Learning: Systematic Search, Analysis, and Comparison of Two Measurement Scales

JMIR Mhealth Uhealth 2021;9(4):e25377

URL: https://mhealth.jmir.org/2021/4/e25377

doi: $\underline{10.2196 / 25377}$

PMID:

CTehmina Gladman, Grace Tylee, Steve Gallagher, Jonathan Mair, Rebecca Grainger. Originally published in JMIR mHealth and uHealth (https://mhealth.jmir.org), 23.04.2021. This is an open-access article distributed under the terms of the Creative Commons Attribution License (https://creativecommons.org/licenses/by/4.0/), which permits unrestricted use, distribution, and reproduction in any medium, provided the original work, first published in JMIR mHealth and uHealth, is properly cited. The complete bibliographic information, a link to the original publication on http://mhealth.jmir.org/, as well as this copyright and license information must be included. 